\title{
Inhalt des dritten Bandes
}

\$ 1. Die Unschärferelationen . . . . . . . . . . . . 4

Anhang zu $\S 1 \ldots \ldots$

\$. 2. Bohrsche Theorie. . . . . . . . . . . . . . . 34

§3. Korrespondenzprinzip. . . . . . . . . . . . . . 57

\$4. Quantenmechanik . . . . . . . . . . . 74

§ 5. Die Analogie Optik-Mechanik . . . . . . . . . . . . 87

\$6. Einfache Beispiele zur Wellenmechanik . . . . . . . 97

§ 7. Zusammenhang zwischen Operatorenrechnung, Quantenmechanik und Wellenmechanik . . . . . . . . . . 116

§ 8. H-Atom. . . . . . . . . . . . . . . . . . . . . . 129

Register . . . . . . . . . . . . 145 